\title{
PARA CONMEMORAR UN ANIVERSARIO: DEL SISTEMA SEXO-GÉNERO A LOS ESTUDIOS QUEER
}

\author{
José Amícola
}

Universidad Nacional de La Plata

Argentina

joseamicola@gmail.com

ORCID: 0000-0002-4218-6312

Fecha de recepción: 23/05/202 I | Fecha de aceptación: 05/06/202 |

Resumen: En oportunidad del aniversario de la revista Anclajes, se revisan sus aportes a las cuestiones del sistema sexo-género desde la última década del siglo $X X$ hasta los más recientes estudios queer. Se señala la integración de estos aportes a una tendencia creciente en el campo de las Humanidades, tanto en los países centrales, como en los periféricos, y se describe la relevancia de algunos de los artículos publicados.

Palabras clave: sexo-género; queer; literatura argentina; siglo XXI.

To commemorate an anniversary: from the sex-gender system to queer studies

Abstract: On the anniversary of the journal Anclajes, this article reviews its contributions to issues of the sex-gender system, from the last decade of the 20th century to the most recent queer studies. I point out the integration of these contributions to a growing trend in the field of Humanities, both in central and peripheral countries, and describe the relevance of some of the articles published in the journal.

Keywords: sex-gender; queer;Argentine literature; XXI century.

\section{Para comemorar um aniversário: do sistema sexo-gênero aos estudos queer}

Resumo: Por ocasião do aniversário da revista Anclajes, suas contribuições para as questões do sistema sexo-gênero são revistas desde a última década do século 20 até os estudos queer mais recentes. Salienta-se a integração dessas contribuições a uma tendência crescente na área de Humanidades, tanto em países centrais como periféricos, e descreve-se a relevância de alguns dos artigos publicados.

Palavras chave: sexo-gênero; queer; Literatura argentina; Século XXI. 

e han cumplido, entretanto, 25 ańos de la revista Anclajes. Quiero centrarme aquí en el itinerario de esta publicación, relacionándolo con los aportes hacia un tema determinado: las cuestiones del sistema sexo-género.

En la profundización del análisis de este dominio, quiero subrayar que no es una casualidad que, en el mismo período en que se ha desarrollado Anclajes, este territorio se haya tornado también uno de mis propios campos de investigación. En efecto, a partir de mediados de la década de los 90 del siglo pasado yo mismo comprobé la necesidad de dedicarme de modo más detallado a la cuestión del sistema sexo-género, porque en ese ámbito se estaban produciendo grandes cambios que no podían dejar de ser atendidos. Por lo tanto, puede muy bien concluirse que esa evolución no es solo la historia del desarrollo de esta revista, sino también una tendencia que se ha ido imponiendo en el campo de las $\mathrm{Hu}$ manidades, tanto en los países centrales, como en los periféricos.

Esta nueva acotación del pensamiento alcanzó efectivamente una teorización más genuina justamente a partir de 1990 con la publicación de los primeros textos de una investigadora como Judith Butler, a quien hay que considerar, en nuestra opinión, una esclarecedora insoslayable en los estudios de género. En este sentido, se podría pensar que Anclajes se colocaría desde su fundación en el centro de la marea de un nuevo modo de pensar los acontecimientos sociales $\mathrm{y}$, dentro de ellos, lo que también podríamos etiquetar como el ámbito de una “ideología de género". Me interesa, por lo tanto, hacer hincapié en lo que esta revista ha venido dando a publicidad en ese dominio, porque es justamente un lugar de disputa; es decir, "la disputa dentro del género" (Gender Trouble), como muy bien lo expresó Butler.

Es sabido que la investigadora norteamericana despejó muchas incertidumbres cuando tuvo la lucidez de pasar por encima de las polémicas más arduas de dentro del propio feminismo, auspiciando un tipo de estudio con una perspectiva menos particularista. Es entonces en ese momento cuando este territorio, que Butler vuelve a acotar, deja de ser solamente el feminismo de barricada, y pasa a contener dentro de sí todas las conductas y posibilidades que implica el concepto siempre tan novedoso y fructífero de "género", nacido primeramente tan solo como diferenciación gramatical y ahora enriquecido con cuestiones que trascienden los problemas lingüísticos, como puede verse, para dar un ejemplo candente, en las más recientes polémicas del así llamado "lenguaje inclusivo". Como se viene diciendo en diferentes foros, lo que parece jugarse en esta última operación del lenguaje inclusivo es sobre todo un proceso de toma de conciencia del sexismo de las lenguas. El hecho de que esta explosión de conocimiento repentino de la injusticia de género que comportan las lenguas, se manifestara tanto en francés, alemán como inglés o español, y así siguiendo, revela que lo importante no es si las lenguas terminan o no por adoptar las reformas, sino en qué medida los hablantes se tornan actores de aquello que dicen. Una marca en la que no se dará marcha atrás a partir de estas escaramuzas lingüísticas del 
feminismo será, por lo pronto, la aceptación de más y más palabras que designen las profesiones liberales encaradas por mujeres que sufrieron siempre una tabuización de masculinismo (como "cirujana" o "directora de orquesta"). Y, a nuestro juicio, eso tiene también que ver con el controvertido "lenguaje inclusivo".

Ahora bien, puede pensarse que una publicación cultural tiene la oportunidad de expresarse con respecto a los temas más urgentes de una sociedad, si no directamente, por lo menos de manera más general, al tratar los temas que ofrece con una visión en la que las cuestiones del sistema sexo-género aparezcan bien iluminadas. Anclajes no esquivó este tipo de problemas, según se puede concluir a partir de la lista de artículos que trataron, en mayor o menor medida, estas cuestiones.

Pasaré a hacer, por lo tanto, una reconsideración de este material, para poner algunos acentos sobre aquello que preocupó a Anclajes en estos 25 años de su existencia.

En primer lugar, me gustaría resaltar aquí que en la revista hubo trabajos de investigación que se dedicaron especialmente a enfatizar el valor de aquellas escritoras, que, por un motivo u otro, estuvieron en la retaguardia de la creación literaria. Así la revista pudo ofrecer mediante los análisis literarios una suerte de rescate contra cierto silencio, llevado adelante por buena parte de la maquinación masculina, que de modo tácito, siempre defendió y promovió con ímpetu las plumas del propio género. Por ello, saludo con alegría que Anclajes se haya ocupado en el 2005 de Angélica Gorodischer, en el 2008 de Silvina Ocampo, en el 2015 de Griselda Gambaro y en el 2017 de las escritoras españolas Almudena Grandes y Ana Rosetti ${ }^{1}$. El hecho de que poner sobre el tapete la obra de estas autoras con perspectiva de género signifique una suerte de "rescate", habla a las claras de la necesidad que tienen los estudios sobre la cultura en general de introducir cualquier tipo de inquietud que tienda a desmontar las injusticias dentro del campo literario. Si la atención prestada a las escritoras antes nombradas es de saludar, este hecho lo es también, porque ocuparse de determinados nombres significa establecer automáticamente una especie de serie o genealogía. Es como si hubiéramos dicho: "Goro-campo-baro-grand-etti". En esa palabra compuesta lo que se descubre es que hay una afinidad, que es lo que la revista, casi sin proponérselo, está marcando.

Un asunto paralelo -y tal vez su coherencia resulte más evidente- ocurre con la serie masculina "diversa"; es decir, de aquellos escritores varones que pu-

1 Mónica Zapata, "El relato policial según Angélica Gorodischer", Anclajes, vol. IX, n. 9, 2005, pp. 175-185; Águeda Pérez, "El falo, la abyección, la identidad: una lectura de 'La calle Sarandí' de Silvina Ocampo", Anclajes, vol. XI-XII, n. ${ }^{\circ} 11-12,2008$, pp. 193-208; Laura Antonella Arnés, "Querer es no poder. A propósito de Lo impenetrable de Griselda Gambaro", Anclajes, vol. XIX, n. ${ }^{\circ}$ 2, julio-diciembre 2015, pp. 1-11; Adriana Virginia Bonatto, "Identidades fronterizas en Ana Rosetti y Almudena Grandes. Hacia una superación del imperativo 'queer"', Anclajes vol. XXI, n. ${ }^{\circ}$ 2, mayo-agosto 2017, pp. 23-40, https://doi.org/10.19137/anclajes-2017-2122. Los artículos citados están disponibles en acceso abierto en https://cerac.unlpam.edu.ar/index.php/ anclajes/index. 
sieron en jaque al mismo sistema, negándose a adoptar de manera automática las consignas de conducta de sus padres. En esta otra serie me gustaría señalar que Anclajes registra en su recorrido la impresión de tres artículos que también vamos a considerar como un ciclo. Así estos análisis aparecieron en (2006) sobre las obras de Pedro Lemebel y Manuel Puig, mientras que más cerca de nosotros (en 2012) fue publicado el texto sobre otro escritor imposible de olvidar en la serie como Néstor Perlongher ${ }^{2}$.

$\mathrm{Si}$ estas dos series paralelas y complementarias antes mencionadas pueden verse como aciertos de la focalización de la revista, no es menos cierto que esta publicación se ha ocupado también de manera enfática de aquella vertiente de las cuestiones de género que llamamos ahora queer (gracias a un préstamo lingüístico venido del Norte). No es un dato menor que así Anclajes se haya hecho eco del dossier de la Revista Iberoamericana (con sede en Pittsburgh), donde el tema ya había sido tratado en forma particular hace una década ${ }^{3}$. En este sentido, la revista pampeana está ayudando a despejar algunas incógnitas con respecto a la palabra "queer" (con sentido de "torcido") que ya ha ganado difusión masiva, pero que no siempre es utilizada con la precisión necesaria. En rigor, este término viene siendo tan útil para el tratamiento de estos temas, como lo fue en un momento el concepto de "gay". Lo cierto es que si "gay" reemplazó con éxito la patológica figura que se escondía detrás de la noción de "homosexualidad" es porque las pautas científicas sobre los cuerpos sexuados habían cambiado fundamentalmente alrededor de mediados del siglo XX. Sin embargo, la historia no se detuvo allí y los ríos siguieron corriendo bajo los puentes. En realidad, la designación de lo "gay" implicaba una esencia y determinación de características siempre fijas, que ahora el nuevo término de "queer" viene a poner en entredicho, pues la nueva conciencia sobre las conductas humanas se determina ahora por su mutabilidad y carencia de fijeza (Amícola Un brillo 89 y ss.). De hecho, la diseminación mundial de la palabra gay fue positiva en más de un sentido, porque, bajo ese estandarte que hablaba de una inmutabilidad de datos, se avalaba una comunidad de intereses estables y, por lo tanto, esa unidad permitía el abordaje hacia la lucha por reivindicaciones y dignidad para un grupo definido como un coto diferente. Así fue posible que la mayoría de los países entendiera a qué se referían las festividades del "Orgullo Gay", porque había debajo de esos conceptos la seguridad de una definición de qué significaba "ser gay”. Las cosas fueron cambiando en las últimas décadas, sin embargo, y ahora también el término "gay" empieza a parecer estrecho de miras, especialmente

2 Marta Urtasun, "Locas que importan: Crónicas de sidario de Pedro Lemebel", Anclajes, vol. X, n. ${ }^{\circ}$ 10, 2006, pp. 201-213; Mariano Oliveto, "Dispositivos confesionales: sexualidad, saber y verdad en dos novelas de Manuel Puig", Anclajes, vol. X, n. ${ }^{\circ}$ 10, 2006, pp. 157-176; Javier Gasparri, "Poesía y política en Néstor Perlongher", Anclajes, vol. 16, n 1, enero-junio 2012, pp. 17-38.

3 Martínez, Luciano, Dossier "Transformación y renovación: los estudios lésbicos-gays y queer latinoamericanos", Revista Iberoamericana, vol. LXXIV, n. ${ }^{\circ} 225$, octubre-diciembre 2008, https:// revista-iberoamericana.pitt.edu/ojs/index.php/Iberoamericana/issue/view/194/showToc. 
porque congela a los individuos en un marco fijo. Desde hace un tiempo las comunidades de la disidencia sexual comprendieron que para lograr la identidad "gay-lésbica" se barrieron unas cuantas cosas bajo la alfombra. El término echado a rodar ahora como "torcido" viene a desbaratar tanta adaptación a la belleza y estabilidad del período anterior, poniendo sobre el tapete no las esencias, sino el movimiento y la mutabilidad de las sexualidades. En este sentido, la "queerness" es tan importante como el lenguaje inclusivo, porque revela la movilidad de los significantes.

Si Anclajes ha pasado a organizar dossiers en torno al sistema sexo-género en los últimos años, esto significa también que se ha gestado una coherencia en su política editorial con respecto al tema. Me regocija, por lo tanto, encontrar en esas carpetas temáticas no solo las cuestiones de feminismo y violencia, sino también aquellas que tratan la disidencia desde los últimos módulos a que nos referíamos más arriba; en especial aquellos trabajos que se centran en las perspectivas de los estudios queer y de las masculinidades. Nos referimos, por ello, especialmente al dossier sobre el último de los temas, aparecido en 2018, a cargo de Jorge Peralta; así como el dedicado a la cuestión queer organizado por Ángeles Mateo del Pino en el $2019^{4}$.

En estas carpetas temáticas que Anclajes nos ha acostumbrado ahora a encontrar en su colección existe, entonces, un presupuesto que, en nuestra lectura, tiene que ver con la evolución de la propia trayectoria de los estudios de "género", cuando a mediados de los años 50 del siglo pasado se vio la necesidad entre los investigadores norteamericanos de proveerse de un nuevo concepto para cubrir aquello que empezaba en ese momento a saltar a la vista como una laguna conceptual. Pero, todavía hay algo más, esta revista está respondiendo en su conformación a una nueva visión del feminismo en su conjunto, al implicarse en un debate que insiste en la inclusión del varón en la polémica; $y$, en este sentido, estamos convencidos de que aquí es donde los aportes de la ya mencionada Judith Butler son los que han hecho posible tomar por atajos más expeditivos y lógicos para responder a todas las cuestiones de las relaciones entre los polos de lo masculino y de lo femenino, donde lo que importa es la colaboración de cada uno de nosotros, independientemente del género que nos haya sido asignado y el que asumamos.

Y quiero terminar estas reflexiones con una cita, tomada del libro de Gianni Vattimo La sociedad transparente, porque ella representa a las claras el lugar donde Anclajes ha querido colocarse:

Filósofos nihilistas como Nietzsche o Heidegger (pero también pragmáticos como Dewey o Wittgenstein), al mostrarnos que el ser no coincide necesariamente con lo

4 Mateo del Pino, Ángeles, Dossier "Lecturas somatopolíticas. Rare and crippled multitudes (queer / cuir-crip)", Anclajes, vol. XXIII, n. ${ }^{\circ} 3$, septiembre-diciembre 2019, https://doi.org/10.19137/ anclajes-2019-2331; Peralta, Jorge, Dossier "Literatura, masculinidades y diversidad sexual", Anclajes, vol. XXII, n. ${ }^{\circ}$ 3, septiembre-diciembre 2018, https://doi.org/10.19137/anclajes-2018-2231. 
que es estable, fijo y permanente, sino que tiene que ver más bien con el evento, el consenso, el diálogo y la interpretación, se esfuerzan por hacernos capaces de percibir esta experiencia de oscilación del mundo posmoderno como chance de un nuevo modo de ser (quizás al fin) humano. (132)

\section{Referencias bibliográficas}

Amícola, José. Un brillo concheperla. Teoría queer y literatura latinoamericana. La Plata, Editorial de la Universidad Nacional de La Plata, EDULP, 2021.

Butler, Judith. Gender Trouble. Feminism and the Subversion of Identity. New York/Londres, Routledge, 1990.

Vattimo, Gianni. La sociedad transparente. 1989. Barcelona, Paidós, 1990. 